\title{
Task-Dependent Role for Dorsal Striatum Metabotropic Glutamate Receptors in Memory
}

\author{
Mark G. Packard, ${ }^{1}$ Stefano F. Vecchioli, ${ }^{2}$ Jason P. Schroeder, ${ }^{1}$ and Antonella Gasbarri ${ }^{2}$ \\ ${ }^{1}$ Department of Psychology, Yale University, New Haven, Connecticut 06520-8025, USA; ${ }^{2}$ Department of Science and Biomedical Technology, \\ Laboratory of Human Physiology, School of Medicine, University of L'Aquila
}

\begin{abstract}
The effect of post-training intradorsal striatal infusion of metabotropic glutamate receptor (mGluR) drugs on memory consolidation processes in an inhibitory avoidance (IA) task and visible/hidden platform water maze tasks was examined. In the IA task, adult male Long-Evans rats received post-training intracaudate infusions of the broad spectrum mGluR antagonist $\alpha$-methyl-4-carboxyphenylglycine (MCPG; 1.0, $2.0 \mathrm{mM} / 0.5 \mu \mathrm{L}$ ), the group I/II mGluR agonist 1-aminocyclopentane-1,3-carboxylic acid (ACPD; 0.5 or $1.0 \mu \mathrm{M} / 0.5 \mu \mathrm{L}$ ), or saline immediately following footshock training, and retention was tested $24 \mathrm{~h}$ later. In the visible- and hidden-platform water maze tasks, rats received post-training intracaudate infusions of ACPD (1.0 $\mu$ M), MCPG $(2.0 \mathrm{mM})$, or saline immediately following an eight-trial training session, followed by a retention test $24 \mathrm{~h}$ later. In the IA task, post-training infusion of ACPD $(0.5$ and $1.0 \mu \mathrm{M})$ or MCPG $(1.0$ and $2.0 \mathrm{mM})$ impaired retention. In the IA and visible-platform water maze tasks, post-training infusion of ACPD (1.0 $\mu \mathrm{M})$, or MCPG $(2.0 \mathrm{mM})$ impaired retention. In contrast, neither drug affected retention when administered post-training in the hidden-platform task, consistent with the hypothesized role of the dorsal striatum in stimulus-response habit formation. When intradorsal striatal injections were delayed $2 \mathrm{~h}$ post-training in the visible-platform water maze task, neither drug affected retention, indicating a time-dependent effect of the immediate post-training injections on memory consolidation. It is hypothesized that MCPG impaired memory via a blockade of postsynaptic dorsal striatal mGluR's, while the impairing effect of ACPD may have been caused by an influence of this agonist on presynaptic "autoreceptor" striatal mGluR populations.
\end{abstract}

Glutamatergic neural transmission is mediated through activation of ionotropic and metabotropic family receptors. Ionotropic glutamate receptors are involved in fast excitatory neurotransmission and consist of NMDA, and AMPA/ kainate receptors subtypes. The metabotropic glutamate receptors (mGluRs) currently consist of eight subtypes classified in three groups (group I: mGluR1 and mGluR5; group II: mGluR2 and mGluR3; and group III: mGluRs 4, 6, 7, and 8). mGluRs are linked to $G$ proteins, activation of which influence various intracellular second-messenger signaling pathways (for reviews, see Schoepp et al. 1990; Conn and Pin 1997; Pin and Duvoisin 1997).

Recent evidence suggests a role for mGluR function in learning and memory processes in rats (for reviews, see Reidel 1996; Holscher et al. 1999). For example, pretraining intracerebroventricular (ICV) infusion of the broad spectrum (i.e., non-group-specific) metabotropic receptor antagonist $\alpha$-methyl-4-carboxyphenylglycine (MCPG) impairs acquisition of shock-reinforced spatial alternation learning (Riedel et al. 1994) and spatial learning in a water maze

${ }^{3}$ Corresponding author.

E-MAIL Mark.Packard@yale.edu; FAX (203) 432-4671.

Article and publication are at www.learnmem.org/cgi/doi/10.1101/ $\operatorname{lm} .37401$.
(Richter-Levin et al. 1994; Bordi et al. 1996). In addition, post-training ICV injection of MCPG impairs retention of lever-press learning in mice (Mathis and Ungerer 1999) and passive avoidance behavior in rats (Riedel 1996), suggesting a role for mGluRs in memory storage processes (McGaugh 1966; 2000). Studies using intracerebral drug injections suggest a role for both hippocampal (Ohno and Watanabe 1998; Frohardt et al. 1999) and amygdala (Bianchin et al. 2000) mGluRs in memory.

The rat dorsal striatum (i.e., caudate-putamen) receives a prominent glutamatergic projection from virtually all regions of the neocortex (i.e., the corticostriatal projection system; Fonumm et al. 1981), as well as various thalamic nuclei (for review, see Ottersen 1995). The dorsal striatum is hypothesized to be selectively involved in stimulus-response (S-R) learning and memory (for an early proposal involving nonhuman primates, see Mishkin and Petri [1984]), a view supported by findings of task-dependent effects (i.e., double dissociations) following lesion (Packard et al. 1989; Packard and McGaugh 1992; Kesner et al. 1993; McDonald and White 1993) or post-training drug manipulations of this structure (Packard and White 1991; Packard et al. 1994; Packard and Teather 1997, 1999; Packard 1999). It has been suggested that glutamatergic input to the dorsal

LEARNING \& MEMORY 8:96-103 @ 2001 by Cold Spring Harbor Laboratory Press ISSN1072-0502/01 \$5.00

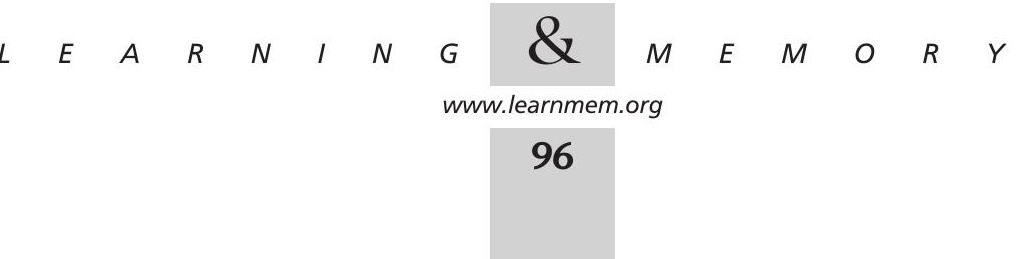


striatum provides, in part, sensory information underlying the formation of S-R associations (White 1989). Consistent with this hypothesis, post-training intradorsal striatal infusions of glutamate selectively enhance memory in a visibleplatform water maze task in which rats are trained to approach a cued escape platform that is located in a different maze location on each trial (Packard and Teather 1999). Intradorsal striatal injections of glutamate also enhance response learning in a cross-maze task in which a specific body-turn direction is consistently reinforced (Packard 1999).

Various mGluR subtypes have been identified in the rat dorsal striatum (Sladeczek et al. 1985; Shigemoto et al. 1992; Testa et al. 1994), and previous studies have investigated the role of these receptors in motor behavior (Sacaan et al. 1991; Smith and Beninger 1996). Other evidence suggests a role for dorsal striatal mGluRs in various forms of long-term synaptic plasticity, including long-term depression and long-term potentiation (e.g., Lovinger 1995; Calabresi et al. 1999). However, to our knowledge no study has investigated a possible role for dorsal striatal mGluRs in

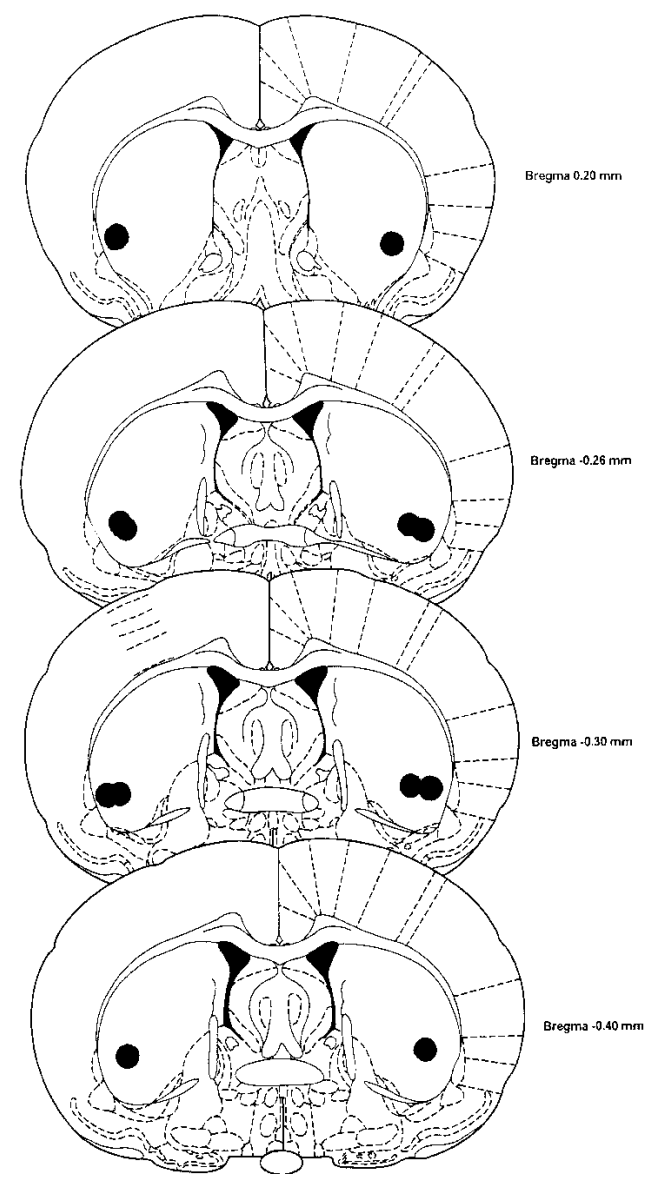

Figure 1 Injection needle tip locations in the dorsal striatum (shown with overlap) and ranging from $0.20-0.40 \mathrm{~mm}$ AP from bregma (from atlas of Paxinos and Watson 1986). memory. Therefore, we examined the effects of post-training intrastriatal infusion of MCPG and ACPD on memory in an inhibitory avoidance task and a visible-platform water maze task. We also examined the effects of post-training intrastriatal infusion of ACPD and MCPG on retention in a hippocampus-dependent (Morris et al. 1982) hidden-platform water maze task. Importantly, this task has the same primary motor (swimming), sensory (visual), and motivational (aversive) properties as the visible platform task. However, because rats are required to swim to a hidden platform in a fixed location from different starting points around the maze perimeter, this task is presumed to involve the acquisition of cognitive or relational spatial information. In view of evidence that the dorsal striatum plays a mnemonic role in S-R habit formation (e.g., Packard et al. 1989; Packard and McGaugh 1992; White 1997), we hypothesized that in the water maze, dorsal striatal mGluR's would selectively influence retention in the visible platform task.

\section{RESULTS}

\section{Inhibitory Avoidance}

A one-way analysis of variance (ANOVA) computed on the training day crossover latencies (i.e., before the posttraining injections), revealed no significant group differences $(F[4,37]=0.14$, n.s. data not shown), indicating that any differences in retention test performance among the treatment groups were not caused by differential crossover latencies on the training day.

The effects of post-training intradorsal striatal infusions of MCPG and ACPD on retention in the inhibitory avoidance task are illustrated in Figure 2. A one-way ANOVA computed on the test-day crossover latencies revealed a significant group effect $(F[4,37]=4.57, P<0.01)$. Scheffe post hoc tests $(P<0.05)$ revealed that the retention test escape la-

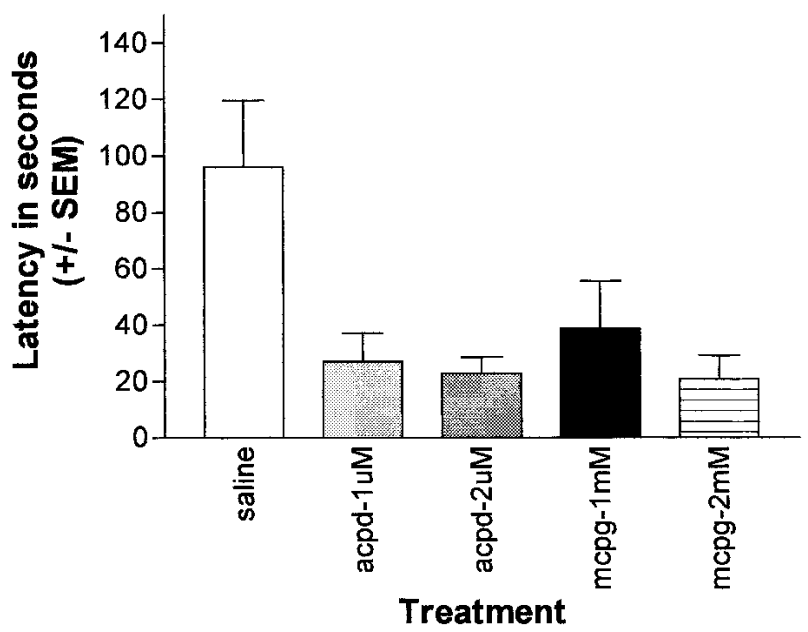

Figure 2 Effects of intradorsal striatal infusions of 1-aminocyclopentane-1,3-carboxylic acid and $\alpha$-methyl-4-carboxyphenylglycine on retention in an inhibitory avoidance task.

$$
\begin{array}{lllllllllllllll}
L & E & A & R & N & I & N & G & \mathbb{Q} \\
\text { www.learnmem.org } & & & & & & & & &
\end{array}
$$


tencies of rats receiving intrastriatal infusions of ACPD 0.5 $\mu \mathrm{M}(F=2.69)$, ACPD $1.0 \mu \mathrm{M}(F=3.64)$, MCPG $1.0 \mathrm{mM}$ $(F=3.01)$, and MCPG $2.0 \mathrm{mM}(F=3.42)$, were all significantly lower than those of saline controls, indicating a memory-impairing effect of the metabotropic receptor drugs.

\section{Visible-Platform Water Maze Task}

In animals trained in the visible-platform task, a two-way repeated-measure ANOVA computed on training-day escape latencies revealed no significant group differences $(F[5,42]=$ 0.433 , n.s.), or Group $\times$ Trial interaction $(F[5,35]=0.1 .13$, n.s.). A significant trial effect $(F[5,7]=82.24, P<0.01)$ indicated that the rate of task acquisition was similar in all groups (Fig. 3. top). The lack of group differences in escape latencies during training indicates that any differences in retention test performance among the treatment groups were not caused by differential rates of task acquisition.

The effect of the post-training intradorsal striatal infusion of MCPG and ACPD on retention in the visible-platform
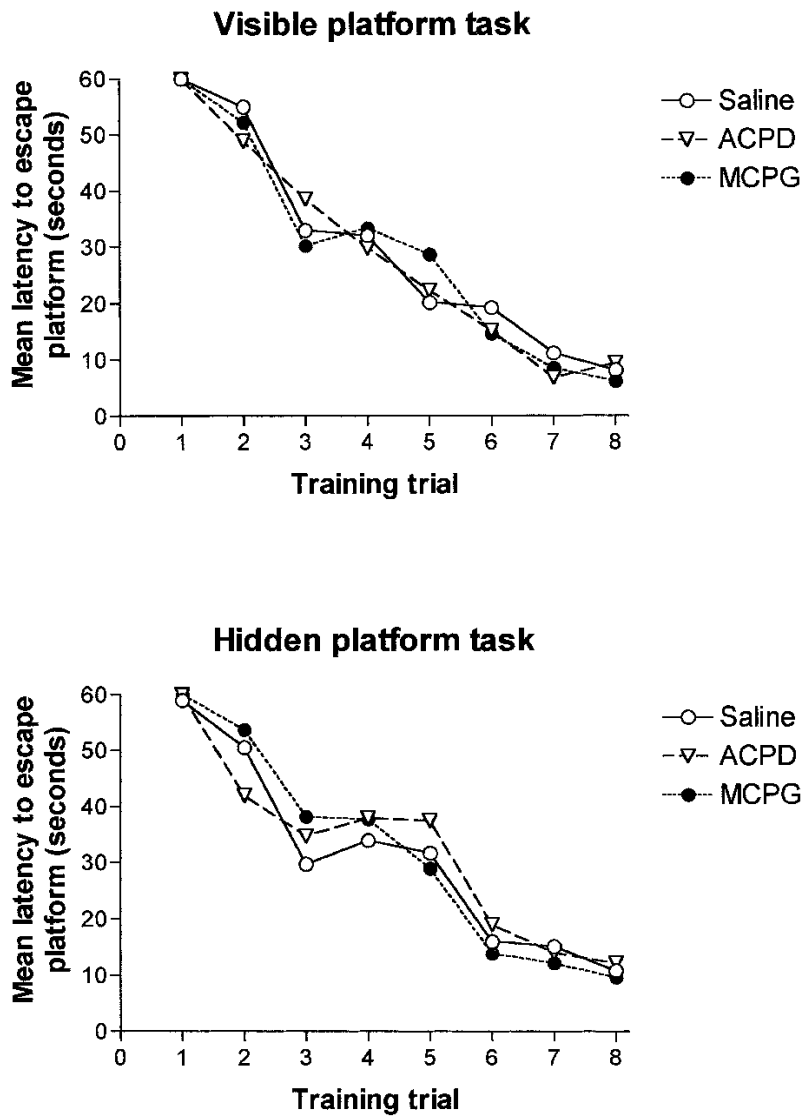

Figure 3 Group mean escape latencies during acquisition (i.e., before receiving post-training intrastriatal drug infusions) of the visible-platform (top) and hidden-platform (bottom) water maze tasks. water maze task is illustrated in Figure 4 (top). A one-way ANOVA computed on the retention test escape latencies revealed a significant group effect $(F[2,23]=3.25, P<0.05)$. Fisher's PLSD post hoc tests showed that the latencies of rats receiving intrastriatal infusion of $\mathrm{MCPG}$ and $\mathrm{ACPD}$ were significantly higher than those receiving intrastriatal saline $(P<0.05)$, indicating a memory-impairing effect of both drugs. Infusions of ACPD or MCPG delayed $2 \mathrm{~h}$ post-training had no effect on retention, as revealed by a nonsignificant group effect $(F[2,17]=0.73$, n.s $)$, indicating that the immediate post-training injections did not impair retention via an action on nonmnemonic or performance factors (McGaugh 1966, 2000).

\section{Hidden-Platform Water Maze Task}

In animals trained in the hidden-platform task, a two-way repeated ANOVA computed on training-day escape latencies (i.e., before the post-training infusions) revealed no significant group differences $(F[2,14]=0.39$, n.s.), or group $\times$ trial interaction $(F[2,14]=1.31$, n.s. $)$. A significant trial effect $(F[2,7]=35.54, P<0.01)$ indicated that the rate of task acquisition was similar in all groups (Fig. 3; top). The effect of the post-training intradorsal striatal infusion of MCPG and ACPD on retention in the hidden-platform water maze task is illustrated in Figure 4 (bottom). A one-way ANOVA computed on the retention-test escape latencies revealed a nonsignificant group effect $(F[2,15]=0.57$, n.s.), indicating that there that there were no effects of intrastriatal infusion of either ACPD or MCPG on memory in the hidden-platform water maze task.

\section{DISCUSSION}

\section{Role for Dorsal Striatal mGluRs in Memory}

Post-training intradorsal striatal infusion of the broad-spectrum mGluR antagonist MCPG, and the group I/II mGluR agonist ACPD, impaired memory in inhibitory-avoidance and visible-platform water maze tasks. Intrastriatal injections of ACPD and MCPG that were delayed until $2 \mathrm{~h}$ posttraining failed to influence retention in the visible-platform water maze task. The time-dependent nature of the intrastriatal mGluR drug infusions suggests an effect on memory consolidation processes (McGaugh 1966, 2000). The hidden-platform and visible-platform water maze tasks share similar motor (swimming), sensory (visual), and motivational (escape/aversive) characteristics. Therefore, in addition to the time-dependent nature of the post-training treatments, the dissociation observed between the effects of intradorsal striatal infusions of MCPG and ACPD in the two water maze tasks also argues against a nonmnemonic interpretation of the drug effects. For example, a proactive influence of the drugs on swim speed can be ruled out as an explanation of the retention-impairing effects of post-train-

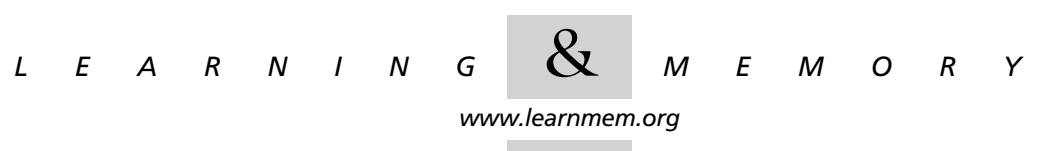



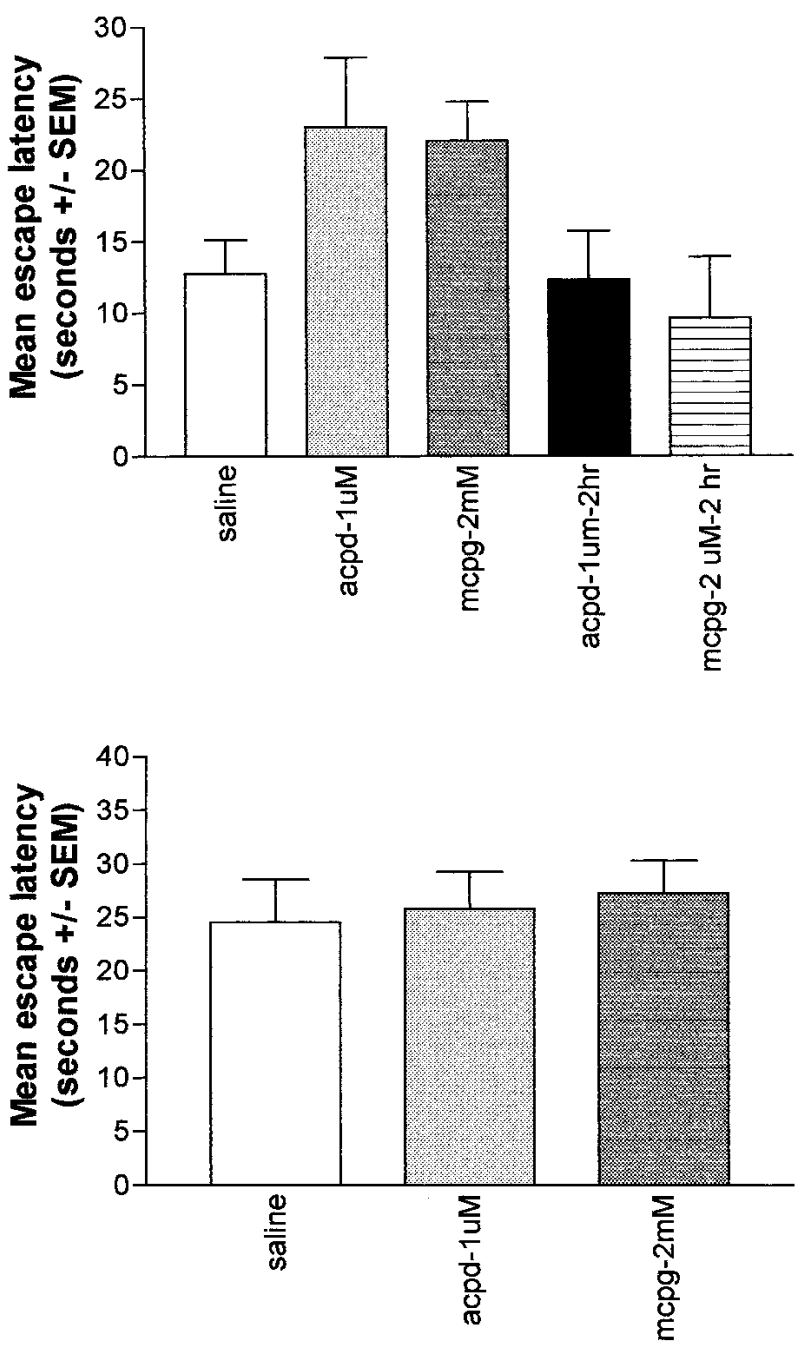

Figure 4 Effects of intradorsal striatal infusions of 1-aminocyclopentane-1,3-carboxylic acid and $\alpha$-methyl-4-carboxyphenylglycine on retention in visible-platform (top) and hidden-platform (bottom) water maze tasks. "2-hr" refers to rats given delayed ( $2 \mathrm{~h}$ ) post-training injections in the visible platform task.

ing MCPG and ACPD, because such an effect would be expected to impair performance in both water maze tasks.

It should be noted that in the absence of autoradiographic analysis, the possibility that the drugs may have affected retention via spread to other brain regions cannot be completely ruled out. However, lesion studies implicate the dorsal striatum in acquisition of inhibitory avoidance and visible-platform water maze tasks (e.g., Neill and Grossman 1971; Winocur 1974; Packard and McGaugh 1992; McDonald and White 1994), providing converging evidence consistent with the hypothesis that the drug infusions acted within the dorsal striatum to affect memory consolidation in this study. Other post-training drug infusion studies also indicate a time-dependent role for the dorsal striatum in memory-consolidation processes in inhibitory avoidance and visible-platform water maze tasks (e.g., Prado-Alcala et al. 1981; Packard et al. 1994, 1996; Packard and Teather 1997, 1999).

\section{Possible Mechanisms of Mnemonic Function of Dorsal Striatal mGluRs}

Activation of mGluRs can influence synaptic transmission in the central nervous system by modulating both postsynaptic receptors and neurotransmitter releaser at presynaptic receptor sites (for review, see Bordi and Ugolini 1999), and these two synaptic sites of drug action may be relevant for understanding the apparently paradoxical finding that intrastriatal infusion of both an mGluR agonist (ACPD) and antagonist (MCPG) impaired memory. We have observed previously that post-training intrastriatal infusion of the NMDA receptor antagonist AP5 impairs memory in the visible-platform water maze task (Packard and Teather 1997), and recent findings indicate that activation of group I metabotropic receptors enhances glutamatergic NMDA responses in the rat striatum (Pisani et al. 1997). Taken together, these findings raise the possibility that a blockade of postsynaptic group I mGluRs by MCPG may dampen NMDA-mediated neurotransmission and lead to memory impairment in this task similar to that produced by AP5. The group I/II mGluR receptor agonist ACPD modulates glutamatergic transmission in the striatum in part via activation of presynaptic autoreceptors located at corticostriatal synapses, resulting in a reduction in the amplitude of excitatory postsynaptic currents (Lovinger et al. 1993a). In view of evidence that post-training intrastriatal infusions of glutamate enhance memory (Packard and Teather 1999), reductions in glutamatergic transmission as a result of any selective autoreceptor activation by ACPD would be expected to impair memory. Further development and testing of metabotropic glutamate receptor drugs possessing greater subtype selectivity than the fairly broad-spectrum agents used here is necessary to directly examine the possibility that the memory-modulatory effects of intradorsal striatal injection of mGluR drugs can involve action at multiple synaptic sites.

Interactions between metabotropic receptor function and striatal GABAergic (Stefani et al. 1994) and dopaminergic (e.g., Sacaan et al. 1992; Smith and Beninger 1996) activity may also in part mediate the mnemonic effects of mGluR agents. Both dopamine and GABA function have been implicated in post-training memory processes occurring in the dorsal striatum mediating retention in inhibitory avoidance (Salado-Castilla et al. 1996), and simultaneous visual discrimination tasks (Packard and White 1991). In addition, the activity of mGluRs has been implicated in two forms of striatal synaptic plasticity: long-term depression and long-term potentiation (Calabresi et al. 1992; Lovinger and Tyler 1996; Calabresi et al. 1999). Although the relationship between these forms of striatal plas-

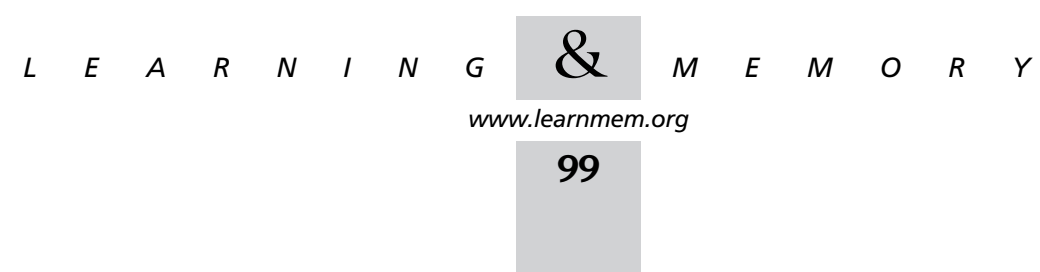


ticity and the mnemonic functions of this structure is unknown, one basic assumption of the hypothesized link between these forms of plasticity and adaptive behavior is that intrastriatal administration of mGluR drugs would be expected to influence striatal-dependent memory, a notion supported by the present findings.

\section{Task-Dependent Role of Dorsal Striatal mGluRs in Memory}

Post-training intradorsal striatal infusions of MCPG and ACPD at doses that impaired memory in a visible-platform water maze task did not affect retention in a hidden-platform water maze task. It is conceivable that other doses of MCPG and ACPD may prove effective in this task when infused into the dorsal striatum. However, post-training intrastriatal infusion of a range of three doses of glutamate and the NMDA receptor antagonist AP5 also do not impair memory in the hidden-platform water maze task and, like ACPD and MCPG, selectively influence memory in the visible-platform task (Packard and Teather 1997, 1999). The task-dependent nature of the memory-modulatory effects of intradorsal striatal infusion of mGluR drugs raises the question of how the psychological operating principles that distinguish these two water maze tasks might be understood. One suggestion is that acquisition of the dorsal striatal-dependent (e.g., Packard and McGaugh 1992; McDonald and White 1994) visible-platform water maze task, in which the cued platform moves to a new spatial location on each trial, involves the ability of a specific visual stimulus $(S)$ to evoke an approach response $(R)$, a form of learning in which $S-R$ associations could support task acquisition. In contrast, acquisition of the hippocampus-dependent (Morris et al. 1982) hidden-platform water maze task may involve learning about spatial relationships among distal visual stimuli and using this cognitive (Tolman 1932; Mishkin and Petri 1984) knowledge to navigate to the escape platform. Therefore, the present findings of a task-dependent role for mGluRs in dorsal striatal memory processes are consistent with the hypothesis that this structure is selectively involved in $S-R$ habit formation (Mishkin and Petri 1984; Packard et al. 1989; Packard and White 1991; Packard and McGaugh 1992, 1994; McDonald and White 1993; White 1997; Packard 1999).

Previous investigations using intracerebroventricular (ICV) injections of MCPG have revealed task-dependent effects consistent with the hypothesis that mGluRs have a selective role in hippocampal-dependent memory. For example, pretraining ICV infusions of MCPG impaired acquisition of a hidden-platform water maze task but had no effect on acquisition of a water maze task in which a proximal cue was provided on the tank wall directly behind the platform location (Bordi et. al. 1996). In addition, ICV injection of MCPG impaired spatial alternation but did not affect retention of a shock-motivated brightness-discrimina- tion task (Riedel 1996). However, our findings raise the possibility that ICV infusions of the single doses of MCPG used in previous studies may not have adequately affected the ventro-lateral region of the dorsal striatum targeted in this study. The sensitivity of particular brain regions to ICV drug infusions may reflect their relative proximity to the ventricular system, as well as neurotransmitter receptor densities in various structures. Thus, in contrast to the hypothesis that mGluRs play a selective role in hippocampaldependent memory processes (e.g., Riedel 1996), our findings using direct intracerebral drug infusions suggest a wider role for brain mGluRs in memory. This suggestion is consistent with the memory-impairing effects of intra-amygdala infusions of MCPG in avoidance conditioning in rats (Bianchin et al. 2000), the induction of an olfactory memory following mGluR agonist infusion into the accessory olfactory bulb of female rats (Kaba et al. 1994), and the influence of MCPG on avoidance learning in chicks (Holscher 1994; Rickard and Ng 1995). An important constraint is that the effects of mGluR stimulation may ultimately be task dependent within a given brain structure. Thus, intradorsal striatal infusions of ACPD and MCPG selectively influenced memory in the visible-platform water maze task (present study) and intrahippocampal infusions of MCPG selectively blocked context but not discrete-cue conditioning (Frohardt et al. 1999). Other findings from our laboratory indicating task-dependent roles for hippocampal and dorsal striatal dopamine receptors (Packard and White 1991) and NMDA glutamate receptors (Packard and Teather 1997) also support this general notion. Thus, there appears to be an evolutionary conservation of the role of various neurotransmitter systems in different types of memory, at least to the extent that the roles of these systems have been examined in hippocampus-dependent and dorsal striatal-dependent memory processes. It is of interest to determine whether the participation of separate brain systems in different types of memory is ultimately dictated by the nature of the information processed by their respective anatomical inputs and outputs and/or perhaps by differential signal transduction mechanisms at the intracellular level (e.g., Guillou et al. 1999).

\section{MATERIALS AND METHODS}

\section{Subjects}

Subjects were 86 adult male Long-Evans rats (275-300 g). The animals were individually housed in a temperature-controlled $12-\mathrm{h}$ light-dark cycle and given ad libitum access to food and water. Lights were on in the colony from 7 a.m. to 7 p.m.

\section{Apparatus \\ Inhibitory Avoidance}

The IA apparatus was a Gemini Passive Avoidance System (San Diego Instruments) consisting of two enclosed Plexiglas compartments with electrifiable grid floors. The compartments were sepa-

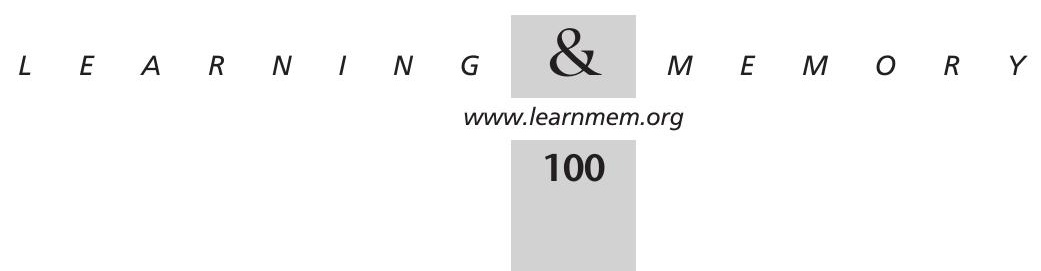


rated by a computer-controlled guillotine door. Animal position within the apparatus was measured via an infrared beam detection system, and administration of electric footshock was delivered via preprogrammed computer instruction.

\section{Water Maze}

The water maze was a black circular tank $1.83 \mathrm{~m}$ in diameter and $0.55 \mathrm{~m}$ in height. The tank was filled with water $\left(25^{\circ} \mathrm{C}\right)$ to a depth of $20 \mathrm{~cm}$. Four starting points (N, S, E, W) were spaced around the perimeter of the tank, dividing the pool into four equal quadrants. A rectangular Plexiglas escape platform was used $(11 \times 14 \times 19$ $\mathrm{cm}$ ). For the visible-platform water maze task, a white golf ball was attached to the center-top of the submerged platform and protruded above the water surface. For the hidden-platform water maze task, the platform was submerged at a depth of $1 \mathrm{~cm}$ below the water.

\section{Surgery}

Before surgery, rats were anesthetized with $50 \mathrm{mg} / \mathrm{kg}$ sodium pentobarbitol $(1.0 \mathrm{~mL} / \mathrm{kg})$. Guide cannulas $(15 \mathrm{~mm}$ long) were implanted bilaterally in the ventro-lateral dorsal striatum using standard stereotaxic techniques. The cannulas were anchored to the skull with jeweler's screws and dental acrylic. Coordinates for the guide cannulas were $\mathrm{AP}=-0.3 \mathrm{~mm}, \mathrm{ML}=4.0 \mathrm{~mm}$ from bregma, and DV $=-5.0 \mathrm{~mm}$ from the skull surface. Coordinates are according to Paxinos and Watson (1986). These coordinates were chosen based on our previous findings that indicated that post-training injections of glutamate (Packard and Teather 1999) and the NMDA receptor antagonist AP5 (Packard and Teather 1997) modulate memory in the visible-platform water maze task following injection into this ventro-lateral region of the dorsal striatum. Other studies have also demonstrated memory-modulatory effects of post-training dopaminergic drug treatments at this striatal site (e.g., Viaud and White 1989; Packard and White 1991). After surgery, stylets were inserted and left in place to insure cannula patency until injections were made. Behavioral training began 7-10 d after surgery.

\section{Drug Preparation and Injection Procedures}

ACPD $(0.5$ and $1.0 \mu \mathrm{M})$ and MCPG (1.0 and $2.0 \mathrm{mM}$; Research Biochemicals International) were dissolved in physiological saline. Intradorsal striatal injections were administered via guide cannulas with 30-gauge injection needles that were connected by polyethylene tubing to $10-\mu \mathrm{L}$ Hamilton microsyringes (Hamilton). The injections ( $0.5 \mu \mathrm{L}$ total volume) were delivered over $52 \mathrm{sec}$ with an electronically controlled syringe pump, and the injection needles (extending $1 \mathrm{~mm}$ from the end of the guide cannulas) were left in place an additional $60 \mathrm{sec}$ to allow for diffusion of solution away from the needle tip.

\section{Histology}

On completion of behavioral testing, animals were anesthetized with a $1-\mathrm{mL}$ injection of sodium pentobarbital $(50 \mathrm{mg} / \mathrm{kg})$ and perfused with saline followed by a $10 \%$ formol-saline solution. Brains were removed and fixed in a $10 \%$ formol solution before slicing. The brains were coronally sliced into $20-\mu \mathrm{m}$ sections through the cannula tract region, stained with cresyl violet, and mounted. The slides were examined for verification of injection needle tip location using the atlas of Paxinos and Watson (1986). Figure 1 illustrates the placement of needle tip positions in the ventro-lateral dorsal striatum.

\section{Behavioral Procedures}

\section{Inhibitory Avoidance Task}

Rats were trained in a one-trial inhibitory avoidance task. On the training trial, the rat was placed into a darkened side of the chamber, facing away from a closed door separating the two compartments. After a 5- sec habituation period, the chamber was illuminated, and the door leading to the dark compartment was opened. After the rat entered the dark compartment, the door closed and a footshock $(0.5 \mathrm{~mA}, 1 \mathrm{sec})$ was delivered. The training day crossover latencies (i.e., before the post-training treatment) were recorded. Rats randomly assigned to treatment groups received injections immediately post-training. The treatment groups included ACPD (0.5 $\mu \mathrm{M}, n=8 ; 1.0 \mu \mathrm{M}, n=8)$, MCPG (1.0 mM, $n=9 ; 2.0 \mathrm{mM}$, $n=9)$, and saline $(n=8)$. Following injection, rats were placed back in their home cages. On the retention test $24 \mathrm{~h}$ later, the rat was placed into the lit compartment as in the training session (i.e., 5- sec dark habituation period), the compartment was illuminated, the door was opened, and the step-through latency (maximum of $300 \mathrm{sec}$ ) was recorded and used as a measure of retention.

\section{Visible-Platform Water Maze Task}

Behavioral procedures were similar to those described previoiusly (Packard and McGaugh 1994; Packard and Teather 1997, 1999). Rats received one training session consisting of eight trials (i.e., swims). On each trial, the animal was placed into the tank facing the wall at one of four designated start points $(\mathrm{N}, \mathrm{S}, \mathrm{E}, \mathrm{W})$ and allowed to escape onto the visibly-cued platform. A different starting point was used on each trial such that each starting point was used twice within the eight trials. The visible escape platform was placed in a different quadrant on each trial such that each of the four quadrants contained the escape platform on two of the eight trials. The locations of the start points were arranged so that the distance to the platform (i.e., proximal or distal) and location of the platform relative to the start point (i.e., left or right) were counterbalanced across the eight trials. If an animal did not escape within $60 \mathrm{sec}$, it was manually guided to the escape platform by the experimenter. After mounting the platform, rats remained on the platform for $20 \mathrm{sec}$. Following each trial, animals were removed from the maze and placed in a holding cage for a 30 -sec intertrial interval. Latency to mount the escape platform was recorded and used as a measure of task acquisition.

Rats were randomly assigned to treatment groups and were given their respective injections immediately post-training (i.e., after the eight trials were completed). The treatment groups included ACPD $(1.0 \mu \mathrm{M}, n=9)$, MCPG $(2.0 \mathrm{mM}, n=9)$, and saline $(n=8)$. These doses were chosen based on their effectiveness in the IA task. Following the post-training injections, rats were placed back in their home cages. A retention test trial was conducted $24 \mathrm{~h}$ after the completion of training. The visible platform was located in a maze quadrant located distal to the starting point on the retention test. Latency to mount the escape platform was recorded on the retention test trial and used as a measure of memory for the previous day's training session.

Additional groups of rats ( $n=6 /$ group) received identical training in the visible-platform water maze task and were given intracaudate infusions of ACPD $(1.0 \mu \mathrm{m})$ or MCPG $(2.0 \mathrm{mM})$ that were delayed until $2 \mathrm{~h}$ following training. The use of delayed injections controlled for possible proactive effects of the immediate post-training infusions on retention-test performance (McGaugh 1966, 2000). The doses used for the delayed injections were se-

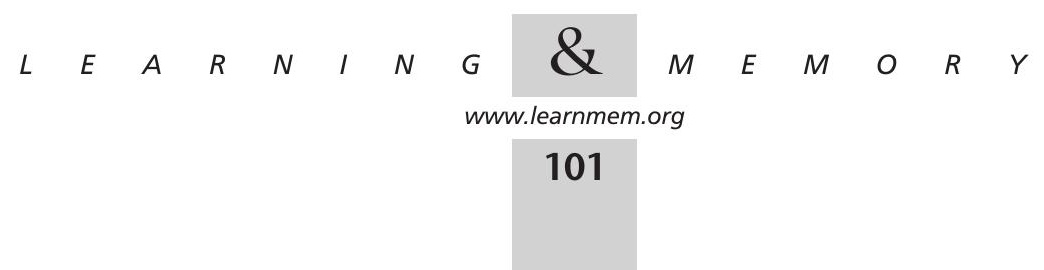


lected following evaluation of the effects of the immediate posttraining infusions

\section{Hidden-Platform Water Maze Task}

Behavioral procedures were similar to those described previously (Packard and McGaugh 1994; Packard and Teather 1997, 1999). Rats received one training session consisting of eight trials (i.e., swims). On each trial, the animal was placed into the tank facing the wall at one of four designated start points $(\mathrm{N}, \mathrm{S}, \mathrm{E}, \mathrm{W})$ and allowed to escape onto the hidden platform. The submerged platform was located in the same quadrant on every trial. A different starting point was used on each trial such that each starting point was used twice within the eight trials. If an animal did not escape within $60 \mathrm{sec}$, it was manually guided to the escape platform by the experimenter. After mounting the platform, rats remained on the platform for $20 \mathrm{sec}$. Following each trial, animals were removed from the maze and placed in a holding cage for a $30-\mathrm{sec}$ intertrial interval. Latency to mount the escape platform was recorded and used as a measure of task acquisition. Rats were randomly assigned to treatment groups and were given their respective injections immediately post-training (i.e., after the eight trials were completed). The doses of ACPD (1.0 $\mu \mathrm{M} ; n=6)$ and MCPG $(2.0 \mathrm{mM} ; n=6)$ used were selected on the basis of their effectiveness when injected post-training in the IA and visible-platform water maze tasks. An additional group of rats received saline injections $(n=6)$.

Following the post-training injections, rats were placed back in their home cages. Retention was tested $24 \mathrm{~h}$ after the completion of training. The submerged escape platform was located in the same quadrant of the maze as it was during training, and a start position located distal to the escape platform was used on the retention test trial. Latency to mount the escape platform was recorded and used as a measure of memory for the previous day's training session.

\section{ACKNOWLEDGMENTS}

This research was supported by National Institutes of Health grant R29MH56973 (M.P.).

The publication costs of this article were defrayed in part by payment of page charges. This article must therefore be hereby marked "advertisement" in accordance with 18 USC section 1734 solely to indicate this fact.

\section{REFERENCES}

Bianchin, M.M., Spanis, C.W., Roesler, R., McGaugh, J.L., and Izquierdo, I. 2000. (+/-)- $\alpha$-methyl-4-carboxyphenylglycine, a metabotropic glutamate receptor blocker, impairs retention of an inhibitory avoidance task in rats when infused into the basolateral nucleus of the amygdala. Brain Res. 852: 436-443

Bordi, F. and Ugolini, A. 1999. Group I metabotropic glutamate receptors: Implications for brain diseases. Prog. Neurobiol. 59: 55-79.

Bordi, F., Marcon, C., Chiamulear, C., and Reggiani, A. 1996. Effects of the metabotropic receptor antagonist MCPG on spatial and context specific learning. Neuropharmacology 35: 1557-1565.

Calabresi, P., Maj, R., Pisani, A., Mercuri, N.B., and Bernardi, G. 1992. Long-term synaptic depression in the striatum: Physiological and pharmacological characterization. J. Neurosci. 12: 4224-4233.

Calabresi, P., Centonze, D., Gubellini, P., Marfia, G.A., and Bernardi, G. 1999. Glutamate-triggered events inducing corticostriatal long-term depression. J. Neurosci. 19: 6102-6110.

Conn, P.J. and Pin, J.P. 1997. Pharmacology and functions of metabotropic gultamate receptors. A. Rev. Pharmac. Toxic. 37: 205-237.

Fonnum, F., Storm-Mathise, J., and Divac, I. 1981. Biochemical evidence for glutamate as a neurotransmitter in corticostriatal and corticothalamic fibres in rat brain. Neuroscience 6: 863-873.

Frohardt, R.J., Guarraci, F.A., and Young, S.L. 1999. Intrahippocampal infusions of a metabotropic glutamate receptor antagonist block the memory of context-specific but not tone-specific conditioned fear. Behav. Neurosci. 113: 222-227.

Guillou, J.L., Rose, G.M., and Cooper, D.M.F. 1999. Differential activation of adenylyl cyclases by spatial and procedural learning. J. Neurosci. 19: 6183-6190.

Holscher, C. 1994. Inhibitors of metabotropic glutamate receptors produce amnestic effects in chicks. Neuroreport 5: 1037-1040.

Holscher, C., Gigg, J., and O'Hara, S. M. 1999. Metabotropic glutamate receptor activation and blockade: Their role in long-term potentiation learning and neurotoxicity. Neurosci. Biobehav. Rev. 23: 399-410.

Kaba, H., Hayashi, Y., Higuchi, T., and Nakashini, S. 1994. Induction of an olfactory memory by the activation of a metabotropic glutamatye receptor. Science 265: 262-264.

Kesner, R.P., Bolland, B.L., and Dakis, M. 1993. Memory for spatial locations, motor responses, and objects: Triple dissociation among the hippocampus, caudate nucleus, and extrastriate visual cortex. Exp. Brain Res. 93: 462-470.

Lovinger, D.M. and McCool, B.A. 1995. Metabotropic glutamate receptor-mediated presynaptic depression at corticostriatal synapses involves mGluR2 or 3. J. Neurophysiol. 73: 1076-1083.

Lovinger, D.M., Tyler, E.C., Fidler, S., and Merritt, A. 1993a. Properties of a presynaptic metabotropic glutamate receptor in rat neostriatal slices. $J$. Neurophysiol. 69: 1236-1244.

Lovinger, D.M., Tyler, E.C., and Merritt, A. 1993b. Short and long-term synaptic depression in rat neostriatum. J. Neurophysiol. 70: 1937-1949.

Mathis, C. and Ungerer, A. 1999. The retention deficit induced by (RS)- $\alpha$-methyl-4-carboxyphenylglycine in a lever press learning task is blocked by selective agonists of either group I or group II metabotropic glutamate receptors. Exp. Brain. Res. 129: 147-155.

McDonald, R.J. and White, N.M. 1993. A triple dissociation of memory systems: Hippocampus, amygdala, and dorsal striatum. Behav. Neurosci. 107: 3-22

-1994. Parallel information processing in the water maze: Evidence for independent memory systems involving the dorsal striatum and hippocampus. Behav. Neural Biol. 61: 260-270.

McGaugh, J.L. 1966. Time-dependent processes in memory storage. Science 153: 1351-1358.

- 2000. Memory-A century of consolidation. Science 287: 248-251.

Mishkin, M. and Petri, H.L. 1984. Memories and habits: Some implications for the analysis of learning and retention. In Neuropsychology of memory (ed. L.R. Squire and N. Butters), pp. 287-296, Guilford, New York.

Morris, R.G.M., Garrud, P., Rawlins, J.N.P., and O'Keefe, J. 1982. Place navigation impaired in rats with hippocampal lesions. Nature 297: 681-683

Neill, D.B. and Grossman, S.P. 1971. Behavioral effects of lesions or cholinergic blockade of the dorsal and ventral caudate of rats. $J$. Comp. Physiol. Psychol. 71: 311-317.

Ohno, M. and Watanabe, S. 1996 Concurrent blockade of hippocampal metabotropic glutamate and $\mathrm{N}$-methyl-D-aspartate receptors disrupts working memory in the rat. Neuroscience 70: 303-311.

Ottersen, O.P., Osen, K.K., and Laake, J.H. 1995. Amino acid transmitters. In The rat nervous system (ed. G. Paxinos), pp. 1017-1040. Academic Press, New York.

Packard, M.G. 1999. Glutamate infused posttraining into the hippocampus or caudate-putamen differentially strengthens place and response learning. Proc. Nat. Acad. Sci. 96: 12881-12886.

Packard, M.G. and McGaugh, J.L. 1992. Double dissociation of fornix and caudate nucleus lesions on acquisition of two water maze tasks: Further evidence for multiple memory systems. Behav. Neurosci. 106: 439-446

1994. Quinpirole and D-amphetamine administration post-training

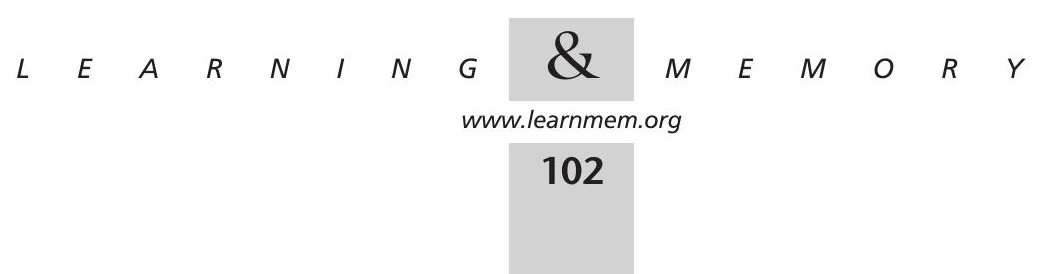


enhances memory on spatial and cued discriminations in a water maze. Psychobiology 22: 54-60.

Packard, M.G. and Teather, L.A. 1997. Double dissociation of hippocampal and dorsal striatal memory systems by post-training intracerebral injections of 2-amino-phosphonopentanoic acid. Behav. Neurosci. 111: $543-551$.

- 1999. Dissociation of multiple memory systems by posttraining intracerebral injections of glutamate. Psychobiology 27: 40-50.

Packard, M.G. and White, N.M. 1991. Dissociation of hippocampus and caudate nucleus memory systems by posttraining intracerebral injection of dopamine agonists. Behav. Neurosci. 105: 295-306.

Packard, M.G., Hirsh, R., and White, N.M. 1989. Differential effects of fornix and caudate nucleus lesions on two radial maze tasks: Evidence for multiple memory systems. J. Neurosci. 9: 1465-1472.

Packard, M.G., Cahill, L., and McGaugh, J.L. 1994. Amygdala modulation of hippocampal-dependent and caudate nucleus-dependent memory processes. Proc. Nat. Acad. Sci. 91: 8477-8481.

Packard, M.G., Introini-Collison, I.B., and McGaugh, J.L. 1996. Stria terminalis lesions attenuate memory enhancement produced by intra-caudate nucleus injections of oxotremorine. Neurobiol. Learn. Mem. 65: 278-282.

Paxinos, G. and Watson, C. 1986. The rat brain in sterotaxic coordinates, 2nd ed. Academic Press, San Diego, CA.

Pin, J.P. and Duvoisin, R. 1995. The metabotropic glutamate receptors: Structure and functions. Neuropharmacology 34: 1-26.

Pisani, A., Calabresi, P., Centonze, D., and Bernardi, G. 1997. Enhancement of NMDA responses by group I metabotropic glutamate receptor activation in striatal neurons. Br. J. Pharmac. 120: $1007-1014$.

Prado-Alcala, R.A., Grinberg, Z.J., Ardritti, Z.L., Garcia, M.M., Prieto, H.G., and Brust-Carmona, H. 1975. Learning deficits produced by chronic and reversible lesions of the corpus striatum in rats. Physiol. Behav. 15: 283-287.

Richter-Levin, G., Errington, M.L., Maegawa, H., and Bliss, T.V.P. 1994 Activation of metabotropic glutamate receptors is necessary for longterm potentiation in the dentate gyrus and for spatial learning Neuropharmacology 33: 853-857.

Rickard, N.S. and NG, K.T. 1995. Blockade of metabotropic glutamate receptors prevents long-term memory consolidation. Brain Res. Bull. 36: 355-259.

Riedel, G. 1996. Function of metabotropic glutamate receptors in learning and memory. Trends Neurosci. 19: 219-224.

Riedel, G., Wetzel, W., and Reymann, K.G. 1994. (R,S)- $\alpha$-methyl-4carboxyphenylglycine (MCPG) blocks spatial learning in rats and long-term potentiation in the dentate gyrus in vivo. Neurosci. Lett. 167: 141-144

Sacaan, A.I., Monn, J.A., and Schoepp, D.D. 1991. Intrastriatal injection of a selective metabotropic excitatory amino acid receptor agonist induces contralateral turning in the rat. J. Pharmacol. Exp. Ther. 259: $1366-1370$

Sacaan, A.I., Bymaster, F.P., and Schoepp, D.D. 1992. Metabotropic glutamate receptor activation produces extrapyramidal motor system activation that is mediated by striatal dopamine. J. Neurochem. 59: $245-251$.

Salado-Castilla, R., Diaz, D., Gaurino, A., Abarado, R., Quirate, G., Prado-Alcala, R.A. 1996. Effects of regional GABAergic blockade of the striatum on memory consolidation. Neuro. Learn. Memory 66: $102-108$.

Schoepp, D.D., Bockaert, J., and Sladeczek, F. 1990. Pharmacological and functional characteristics of metabotropic excitatory amino acid receptors. Trends Pharmacol. Sci. 11: 508-515.

Shigemoto, R., Nakanishi, S., and Mizuno, N. 1992. Distribution of the mRNA for a metabotropic glutamate receptor (mGluR1) in the central nervous system: An in situ hydridization study in adult and developing rat. J. Comp. Neurol. 322: 121-135.

Sladeczek, F., Pin, J.P., Recasens, M., Bockaert, J., and Weiss, S. 1985 Glutamate stimulates inositol phospholipid formation in striatal neurons. Nature 317: 717-719.

Smith, I.D. and Beninger, R.J. 1996. Contralateral turning caused by metabotropic glutamate receptor stimulation in the dorsal striatum is reversed by MCPG, TTX, and cis-flupenthixol. Behav. Neurosci. 110: 282-289.

Stefani, A., Pisani, A., Mercuri, N.B., and Calabresi, P. 1994. Activation of metabotropic glutamate receptors inhibits calcium currents and GABA-mediated synaptic potentials in striatal neurons. J. Neurosci. 14: 6734-6743.

Testa, C.M., Standaert, D.G., Young, A.B., and Penney, J.B. 1994. Metabotropic glutamate receptor mRNA expression in the basal ganglia of the rat. J. Neurosci. 13: 3005-3018.

Tolman, E.C. 1932. Purposive behavior in animals and men. Appleton-Century Crofts, New York.

Tyler, E.C. and Lovinger, D.M. 1995. Metabotropic glutamate receptor modulation of synaptic transmission in corticostriatal co-cultures: Role of calcium influx. Neuropharmacology 34: 939-952.

Viaud, M.D. and White, N.M. 1989. Dissociation of visual and olfactory conditioning in the neostriatum of rats. Behav. Brain Res. 32: 31-42.

White, N.M. 1989. A functional hypotheses concerning the striatal matrix and patches: Mediation of S-R memory and reward. Life Sci. 45: 1943-1957.

- 1997. Mnemonic functions of the basal ganglia. Curr. Opin. Neurobiol. 7:164-169.

Winocur, G. 1974. Functional dissociation within the caudate nucleus of rats. J. Comp. Physiol. Psychol. 86: 432-439.

Received January 10 2001; accepted in revised form January 24, 2001.

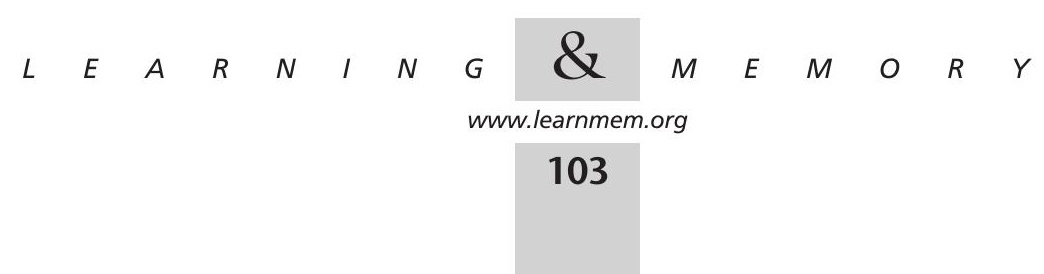

